\title{
Gestão de empreendimentos econômicos solidários na Região Noroeste do Rio Grande do Sul
}

\author{
Noëlle M. P. Lechat \\ Carolina Ritter \\ Fábio R. M. Lemes \\ Tiago Schirmer*
}

\section{Introdução}

A apropriação efetiva dos direitos políticos, econômicos, sociais, culturais, entre eles o direito ao trabalho digno, dos direitos coletivos ao meio ambiente e ao desenvolvimento, é encarada por Sachs (2004, p. 14) como parte integrante do conceito de desenvolvimento. No entanto, nota-se que as medidas tomadas em nome do desenvolvimento levaram o mundo a um cres-

* Doutora em Ciências Sociais pela Unicamp, professora do Programa de Pós-Graduação em Desenvolvimento da Unijuí. Autora do livro A questão de gênero no movimento dos trabalhadores rurais (MST): estudo de dois assentamentos no Rio Grande do Sul. Ijuí - RS: Unijuí, 1997. E-mail: noelle_lechat@hotmail.com. Carolina Ritter - Acadêmica do Serviço Social, bolsista Pibic/ Unijuí. Fábio R. M. Lemes - Economista, ex bolsista Pibex/Unijuí. Tiago Schirmer - Acadêmico de Administração, ex bolsista BIC/ Fapergs.

\begin{tabular}{|c|c|c|c|c|c|}
\hline Civitas & Porto Alegre & v. 7 & n. 1 & jan.-jun. 2007 & p. 175-194 \\
\hline
\end{tabular}


cimento econômico sem aumento proporcional de emprego. Ao projeto de desenvolvimento econômico do capitalismo com seus efeitos desastrosos sobre países, regiões, e populações de excluídos sócio-econômicos se contrapõe um projeto de desenvolvimento alternativo de economia solidária. A emancipação e a melhoria das condições de vida dos trabalhadores dos empreendimentos econômicos solidários são buscadas através do empoderamento dos mesmos, de suas redes e movimentos de base. A economia solidária visa à construção de uma alternativa econômica fortemente embasada nos Direitos Humanos, sem os quais não há desenvolvimento includente, sustentável e sustentado.

Refletir sobre o conceito de autogestão e a realização da sua prática nos empreendimentos econômicos solidários é o propósito deste artigo. Para isso, é feita uma análise estatística e qualitativa das práticas existentes na Região Noroeste do Rio Grande do Sul ${ }^{1}$ (RS). O texto é dividido em quatro partes. Após uma breve introdução sobre o conceito de economia solidária, apresenta-se o perfil desta economia na região estudada, a partir dos resultados do mapeamento realizado para o Sistema de Informação em Economia Solidária (Sies). A seguir são expostas as dificuldades de interpretação dos dados quanto às informações sobre gestão e práticas democráticas nesses empreendimentos e, no final, apresenta-se algumas reflexões sobre o sentido das relações democráticas em empreendimentos econômico solidários e nas empresas capitalistas.

Sob a denominação de economia solidária, às vezes desconhecida como tal até pelos seus próprios integrantes, abriga-se um leque extremamente diverso de empreendimentos econômicos solidários, indo de empresas falidas autogestionadas pelos seus trabalhadores até grupos de produção para o autoconsumo. Geralmente a autogestão é discutida a partir das fábricas recuperadas pelos seus trabalhadores (Vieitez, 1998; Anteag, 2000; Nascimento, 2000; Singer, 2000; Novaes, 2005). Esse tipo de empreendimento não será analisado neste trabalho, pois não os encontramos na região em estudo, a não ser o caso excepcional da Cooperativa dos Produtores de Cana de Porto Xavier - Coopercana.

1 Região dos Conselhos Regionais de Desenvolvimento (Coredes): Fronteira Noroeste, Noroeste Colonial, Missões e Alto Jacuí. 
Para dimensionar as experiências em economia solidária, o Governo Federal instituiu uma Secretaria Nacional de Economia Solidária (Senaes) junto ao Ministério do Trabalho e Emprego (MTE) em 2003. Esta secretaria, com apoio do Fórum Brasileiro de Economia Solidária (Fbes), iniciou um amplo processo de identificação das experiências que poderiam ser caracterizadas de economia solidária, visando constituir um Sistema Nacional de Informações em Economia Solidária (Sies). A Senaes definiu um conjunto de características para identificar as empresas, associações, cooperativas ou grupos de trabalhadores considerados como de economia solidária: organizações coletivas, de caráter permanente, que podem dispor ou não de registro legal, realizam atividades econômicas de produção de bens, de prestação de serviços, de comercialização, de consumo e autoconsumo, de fundos de crédito, formadas por trabalhadores/as ou famílias de trabalhadores que são, na sua quase totalidade, proprietários/as ou co-proprietários/as, exercendo a gestão coletiva das atividades e da alocação dos seus resultados, podendo ainda ser organizações econômicas simples ou complexas (Ministério do Trabalho, 2004).

Concomitante a essa realidade dos empreendimentos econômicos solidários mapeados empiricamente, existe um projeto ideológico que entende a economia solidária como uma proposta socioeconômica, política e cultural que busca o desenvolvimento humano dentro dos princípios democráticos $\mathrm{e}$ de respeito ao meio ambiente, a partir de relações sociais de produção autogestionárias, democráticas e solidárias, antagônicas às do sistema capitalista. Este ideal surge de uma atitude crítica frente ao modelo de desenvolvimento que produz riquezas gerando miséria, subordinando e explorando o trabalho e a natureza, e que vislumbra esta proposta não somente como uma alternativa para a população excluída desse sistema, mas como embrião de uma outra economia. Assim, mesmo sendo necessária a lucratividade dentro da economia solidária para garantir a sustentabilidade dos seus empreendimentos, uma das originalidades desta outra economia é estar no mercado sem se submeter à busca do lucro a qualquer preço.

Assim, os partidários da economia solidária formam um movimento social que se organiza em redes e fóruns para reivindicar políticas públicas de apoio ao novo cooperativismo e de definição de um novo marco legal. Um movimento que se organiza para ganhar a solidariedade da sociedade civil e sua adesão ao comércio solidário. Na tentativa de ganhar força, este movi- 
mento forma parcerias com organizações, governamentais ou não, susceptíveis de fomento e ou apoio a esses empreendimentos.

\section{O perfil dos empreendimentos econômicos solidários na Região Noroeste do RS}

Para conhecer a realidade dos empreendimentos com as características anteriormente citadas e criar um banco de dados nacional para o Sistema Nacional de Informações em Economia Solidária (Sies), foram criadas em todo o país 27 Equipes Gestoras Estaduais (Eges), sob a responsabilidade da Secretaria Nacional de Economia Solidária/ Ministério do Trabalho e Emprego (Senaes/MTE) e do Fórum Brasileiro de Economia Solidária. No Rio Grande do Sul, nas regiões dos Coredes Noroeste Colonial, Fronteira Noroeste, Alto Jacuí e Missões, o levantamento foi coordenado por uma equipe ligada à Incubadora de Economia Solidária da Universidade Regional do Noroeste do Estado do Rio Grande do Sul (Unijuí) . Foram aplicados 313 formulários compostos de 72 questões. Os empreendimentos econômicos solidários encontrados na região abrangem cerca de 62 mil associados e estão assim distribuídos: 136 no Corede Noroeste Colonial, 84 nas Missões, 58 na Fronteira Noroeste e 35 no Alto Jacuí. Após estudo, na última triagem, revelou-se que só 276 desses empreendimentos poderiam ser levados em consideração.

É preciso alertar que o esforço para conseguir abranger todos os grupos de economia solidária da região noroeste do Rio Grande do Sul foi muito grande, pois como sabemos, os estudos nesta área ainda são incipientes e este é o primeiro levantamento sobre o assunto realizado na região. Por esta razão, os dados analisados a seguir podem representar apenas uma "sombra" do que na realidade existe de empreendimentos com esse perfil.

É evidente que todo fenômeno social traz uma carga histórica, cultural, política e ideológica que não pode ser depreendida de um dado estatístico. No entanto, dados estatísticos são interessantes, pois permitem observar uma realidade estruturada. Gurvitch nos adverte que a morfologia e a ecologia dos fenômenos sociais afeta significações, motivos, aspirações, atitudes, crença e valores. Indicadores numéricos podem apontar para problemas cruciais que devem ser analisados de maneira qualitativa. Em função disto, e pelo fato desta pesquisa estar em 
sua fase exploratória, os dados quantitativos apresentados a seguir devem ser considerados apenas como indicativos de uma certa realidade que devemos aprofundar. Iremos então combinar análise quantitativa e qualitativa.

A primeira questão que caracteriza os empreendimentos econômicos solidários (EES) diz respeito à existência ou não de registro legal e da personalidade jurídica assumida pelos grupos legalizados.

\section{Gráfico 1 - Forma de organização dos empreendimentos econômicos solidários da Região Noroeste do RS}

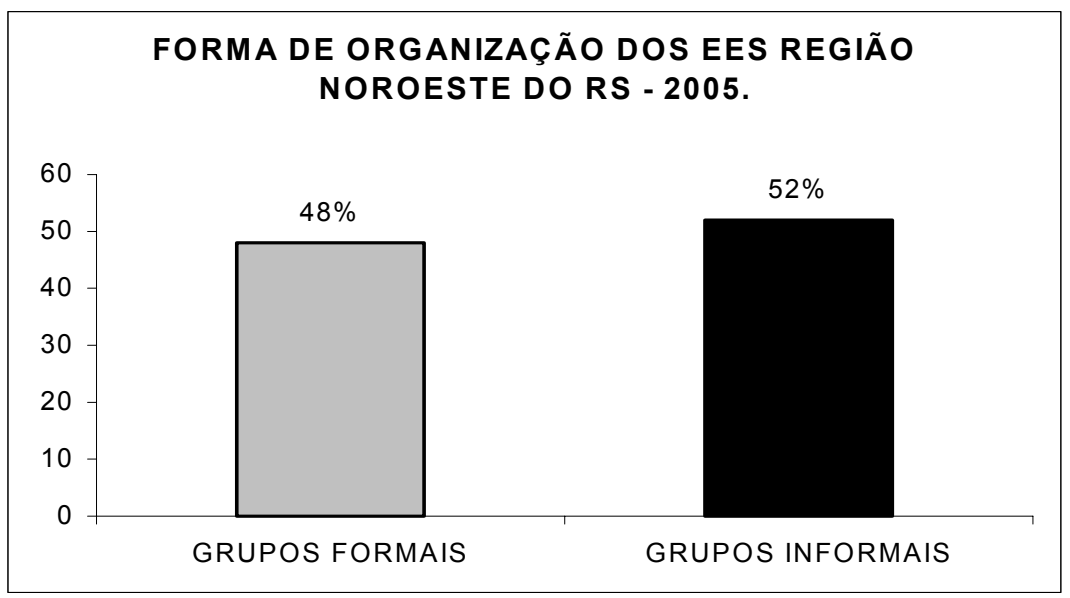

Fonte: Dados Unijuí/mapeamento Sies/Senaes/MTE/2005.

Da análise dos dados resultou que 52,1\% dos 267 empreendimentos que responderam a essa pergunta são grupos informais (Gráfico 1). Essa distribuição reflete uma situação específica da nossa região, pois, no perfil nacional, os grupos informais representam 33\% do conjunto, sendo que na Região Sul essa proporção sobe para $41 \%$.

Os dados de participação de homens e mulheres nos empreendimentos mostram que quanto menor é o empreendimento, maior a tendência a ser composto por mulheres. Nos empreendimentos de até 20 sócios, as mulheres 
são majoritárias (1.350 mulheres e apenas 1.146 homens). Mas no total, o número de homens (38.720) é muito superior ao de mulheres (20.225). Estes dados devem ser analisados com cuidado, pois sabemos do caráter pronunciadamente rural destes empreendimentos. Os maiores dentre eles são cooperativas, por exemplo de crédito ou de eletrificação, e nestas o associado é o chefe de família, quase sempre homem, o que não significa que as mulheres não tenham um papel ativo na produção.

A maioria dos empreendimentos solidários se constituiu a partir de 1990, com gradativa expansão a partir de 2000. Supõe-se que à medida que estes grupos forem se desenvolvendo, poderão eventualmente proceder ao registro legal. Outros grupos não se legalizaram em função de sua natureza. Não são grupos destinados ao mercado, são grupos voltados principalmente à produção de bens e serviços para autoconsumo ou para uso de equipamentos, em geral agrícolas.

No entanto, nos espaços de discussão (fóruns, seminários, oficinas) e mesmo durante as entrevistas do mapeamento, os grupos deixam claro que o registro legal não é uma prioridade, a menos que isto possa resultar em acesso a mercados, caso haja isenção fiscal sobre a produção ou comercialização, ou ainda caso o valor recebido pelo produto ou serviço cubra os custos dos impostos. O mesmo descaso aparece quanto à formalização de estatutos e regimentos.

\section{Gráfico 2 - Distribuição dos empreendimentos econômicos solidários formais da Região Noroeste do RS}

\section{DIVISÃO DOS GRUPOS FORMAIS Região noroeste do RS- 2005}

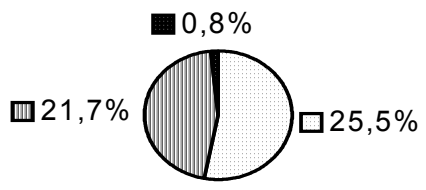

$\square$ Associação
$\square$ Cooperativa
Outra

Fonte: Dados Unijuí/mapeamento Sies/Senaes/MTE/2005. 
Dentre os grupos que possuem registro legal (Gráfico 2), observa-se que $25,5 \%$ são associações. De acordo com dados do mapeamento nacional, essa é a forma de organização mais utilizada pelos empreendimentos econômicos solidários no país, representando um percentual de 54\% (Senaes, 2005). Portanto, embora majoritário em nível nacional, podemos observar que, entre os empreendimentos analisados, tanto na região Sul (34\%), como no Noroeste do RS (25,5\%), essa opção tem importância menor, mas ultrapassa a formalização de tipo cooperativa. Isso porque estas representam $21,7 \%$ dos empreendimentos do Noroeste do RS, porcentagem quase idêntica à da região Sul do país $(22 \%)$, mas bem acima da média nacional (11\%). Isto reflete um fenômeno histórico, há tempos identificado no estado: o espírito cooperativo, principalmente dos agricultores familiares, na sua maioria, de origem européia não-ibérica (Sarria, 2004).

As cooperativas, consideradas empreendimentos econômicos solidários especialmente no meio rural, possuem um diferencial em relação às cooperativas empresariais. Além de serem bem menores e de associarem somente agricultores familiares, as cooperativas rurais são menos burocratizadas e permitem que o associado seja parte efetiva na tomada de decisões.

Os empreendimentos organizados desde o início sob a forma de cooperativas e/ou associações, especialmente no meio rural, recebem geralmente assessoria da Associação Riograndense de Empreendimentos de Assistência Técnica e Extensão Rural (Emater) ${ }^{2}$ ou de prefeituras municipais. A legalização é, nesse caso, entendida como uma prioridade para se ter acesso aos recursos públicos que, em geral, necessitam da pessoa jurídica constituída. Em função disso, é comum os associados não conhecerem plenamente seus estatutos e não terem regimento interno. Em muitos desses empreendimentos manifesta-se a queixa das lideranças a respeito da falta de envolvimento por parte dos associados. Também é comum os grupos iniciarem a atividade com grandes expectativas, que não são alcançadas porque os grupos não estavam preparados para atuar no mercado, não conheciam todas as especificações para a produção e obtenção de registro sanitário e não sabiam dos impostos que incidiam sobre a atividade. Isso acontece porque, geralmente, os projetos

2 A Emater, órgão de extensão rural oficial no Rio Grande do Sul, atua em 484 dos 496 municípios do estado com escritórios municipais. Ela atende principalmente a agricultura familiar, mas também as comunidades indígenas e quilombolas. 
de agroindústria buscam estimular a fabricação de produtos dos quais os agricultores desconhecem as exigências e normas de fabricação, embalagem, rotulagem e transporte, uma vez que os produziam apenas para o consumo familiar. Dois exemplos típicos são os "embutidos" (produtos de origem animal) e os derivados de cana-de-açúcar, em especial a aguardente.

Portanto, o fato de ter o registro legal, ter estatuto e acesso a verbas públicas nem sempre coloca esses empreendimentos em um patamar superior aos grupos que atuam informalmente, com regras acordadas na palavra, sem espaços formais de deliberações, com recursos obtidos através de projetos destinados à unidade familiar de produção agrícola e realizando a comercialização em feiras. Em geral, quando necessitam expedir nota fiscal, por exemplo, isto é feito no bloco de produtor familiar. Evidentemente que esta é uma situação típica dos empreendimentos econômicos solidários do meio rural.

\section{Gráfico 3 - Área de atuação dos empreendimentos econômicos solidários da Região Noroeste do RS}

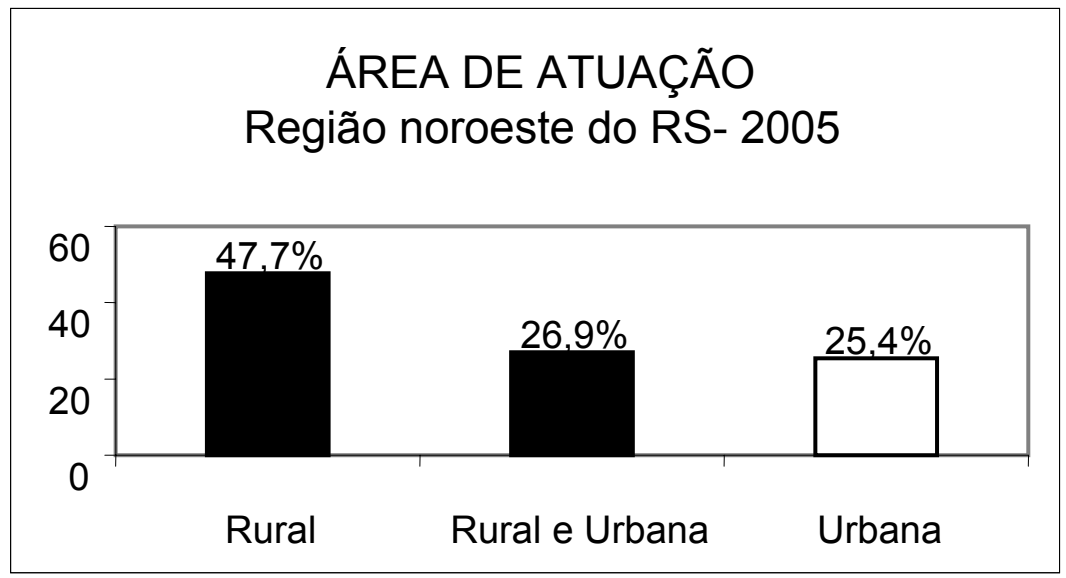

Fonte: Dados Unijuí/mapeamento Sies/Senaes/MTE/2005.

Nesse sentido, os dados do mapeamento nos mostram que, entre 264 empreendimentos que responderam à questão referente à sua área de atuação, 
$47,7 \%$ atuam na área rural, $26,9 \%$ atuam tanto na área rural quanto na urbana e apenas $25,4 \%$ declaram que sua área de atuação é apenas urbana (Gráfico 3). Portanto, $74,6 \%$ dos empreendimentos entrevistados se constituem como propostas alternativas à situação do meio rural, em especial em relação à agricultura familiar, que há cerca de três décadas é dependente da monocultura da soja na região analisada. Para incrementar a renda destes pequenos agricultores através da diversificação, agroindustrialização e associativismo, prefeituras e Emater têm buscado recursos junto a órgãos e instituições estaduais e federais como o Pronaf, Prorenda Rural, RS Rural, etc, especialmente na última década.

\section{Gestão e práticas democráticas em empreendimentos econômicos solidários}

Como sabemos, o conceito de autogestão não é algo novo, ele foi proposto por socialistas utópicos, por anarquistas, pelos sovietes, mas desenvolveu-se com mais força a partir da segunda metade do século XX e retomou vigor com os estudos sobre a economia solidária. Quanto às formas autogestionárias de organização da produção, elas são um elemento fundamental na luta histórica dos trabalhadores desde o início do capitalismo caracterizandose, portanto, como fenômeno social, como práticas sociais historicamente construídas.

Atualmente, o sistema autogestionário ressurgiu para suprir necessidades econômicas, como, por exemplo, a implantação do sistema de gestão para salvar empresas da falência e evitar o desemprego em massa. Teoricamente, a autogestão corresponderia à democracia na economia, considerada como uma característica que qualifica e define a economia solidária (Lisboa, 2005, p. 109).

Essa autogestão na "outra economia" ou economia solidária é caracterizada pelo modo de agir coletivo, que vai além do contrato estabelecido entre os cooperadores. A autogestão não reparte só o poder, mas também os ganhos. Torna-se um meio de dar dignidade e esperança de vida aos sujeitos envolvidos no processo que buscam, além de renda para a sua subsistência, uma mudança na sociedade. (Albuquerque; 2003, p. 20-25). Considerando o conceito de empresa autogestionária, Albuquerque subdividiu-o em quatro 
campos de atuação: o primeiro corresponde à parte social, que deve criar resultados capazes de agradar a todos que dependam da empresa para a sua sobrevivência; o segundo, referente à parte econômica, trata de instituir relações sociais de produção que valorizem o trabalho antes do capital; o terceiro campo refere-se à parte política e trata de criar uma estrutura para compartilhar o poder de decisão respeitando o equilíbrio de forças e os diferentes atores; e o quarto e último campo, corresponde à parte técnica, que pode gerar uma outra forma de organização da divisão do trabalho - modificação significativa na estrutura empresarial, particularmente na organização do trabalho segundo Vieitez e Dal Ri (2001, p. 19). A autogestão, como podemos ver, se relaciona a vários outros princípios da economia solidária, como solidariedade, eqüidade, cooperação e desenvolvimento humano.

As práticas autogestionárias não se limitam ao domínio das empresas, pois podem abranger outras organizações como escolas e associações sem fins lucrativos. Mas aqui vamos focalizar essas práticas nas empresas e empreendimentos econômicos solidários, destacando desde já que a diversidade de campos que abrange o conceito da autogestão vai além de uma simples modalidade de gestão.

A fim de verificar em que medida os empreendimentos pesquisados praticam a autogestão, analisamos, inicialmente, algumas respostas dadas a respeito das suas respectivas instâncias de direção e coordenação. A instância máxima de tomada de decisões de um empreendimento econômico solidário é a "Assembléia Geral dos Sócios" ou "Reunião do Coletivo dos Membros", como foi denominada no questionário. ${ }^{3}$ Essa instância constitui o espaço primordial para o exercício da gestão que, neste caso, toma a forma de autogestão. Nesta assembléia, a totalidade dos integrantes do empreendimento toma as decisões; todo e qualquer assunto relativo ao empreendimento e a seus trabalhadores pode ser discutido; cada sócio tem direito à palavra, sem qualquer restrição; e todos têm igual poder de decisão, representado pelo princípio: uma pessoa, um voto. A assembléia representa a integração democrática, pois igualitária, de todos os trabalhadores. Além de ser um elemento chave do processo democrático, ela é também um momento importante no processo educativo dos trabalhadores. Ela permite a estes se informarem dos

3 No momento da entrevista foi permitido aos grupos responder o que mais se adequava à sua realidade. Assim, as duas alternativas acima citadas foram consideradas equivalentes. 
diferentes aspectos que integram a gestão do empreendimento, desde a compra da matéria-prima até a venda do produto, passando pelas diversas etapas do processo de produção, incluída a delicada questão da remuneração do trabalho e distribuição do excedente, quando houver. Questões financeiras, de marketing, de venda e de investimento podem ser tratadas, bem como as decisões que envolvem o planejamento estratégico. Em geral, é a primeira vez que o trabalhador de um empreendimento se depara com o leque das atividades e responsabilidades de uma empresa. Segundo o art. 38 da lei 5.764, de 16/12/71 que gere o cooperativismo:

A Assembléia Geral dos associados é órgão supremo da sociedade, dentro dos limites legais e estatutários, tendo poderes para decidir os negócios relativos ao objeto da sociedade e tomar as resoluções convenientes ao desenvolvimento e defesa desta, e suas deliberações vinculam a todos, ausentes ou discordantes (Lei do Cooperativismo Brasileiro, 1971).

\section{Gráfico 4 - Instâncias de direção nos empreendimentos econômicos solidários da Região Noroeste do RS}

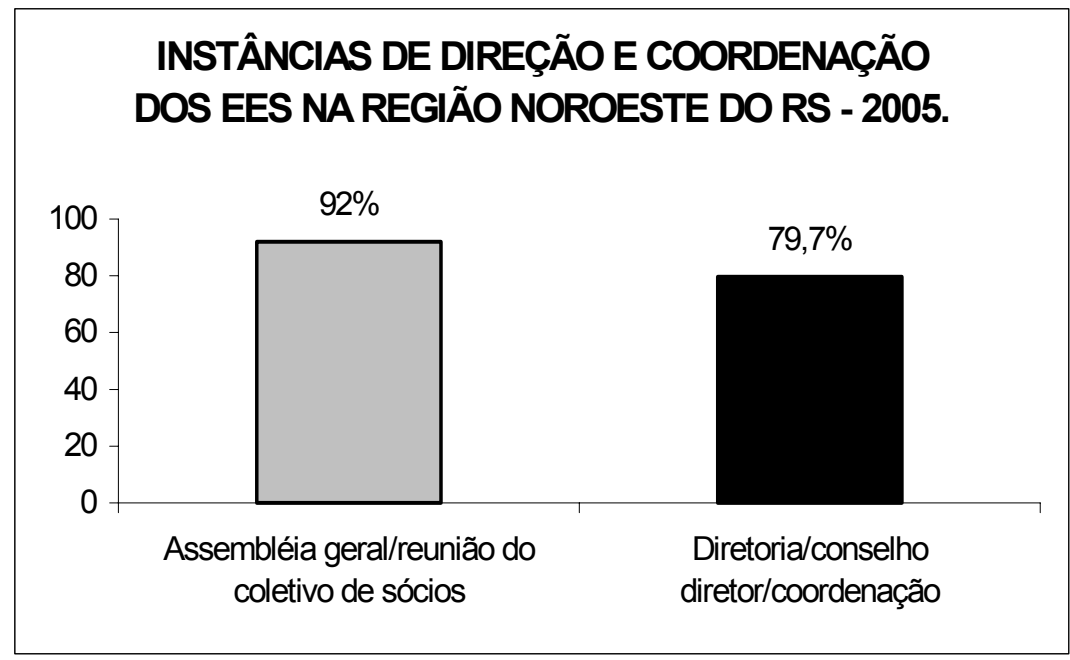

Fonte: Dados Unijuí/mapeamento Sies/Senaes/MTE/2005. 
É evidente que somente uma pesquisa qualitativa vai permitir saber realmente quais são os assuntos tratados nas assembléias e de que maneira isto é feito. Ou seja, é importante saber se os assuntos debatidos em assembléia foram bem compreendidos antes da tomada de decisão.

Existe uma discrepância entre o número de empreendimentos que responderam ter como instância de direção a Assembléia Geral (Gráfico 4) e o número de empreendimentos que informaram a periodicidade das mesmas (Gráfico 5). Se, no primeiro caso, tivemos 71,6\% dos empreendimentos que assinalaram existir este órgão de gestão; no segundo caso, tivemos $92 \%$ de empreendimentos, e somente $8 \%$ afirmaram não realizarem assembléia. Como no primeiro caso existia a possibilidade de múltiplas respostas, é possível ter havido esquecimento na hora da resposta ou do preenchimento. Essa discrepância indica a necessidade de ter-se cuidado redobrado com questionários e estatísticas. Observa-se então que a grande maioria, 92\% dos empreendimentos pesquisados, realiza a Assembléia Geral ou a Reunião do Coletivo de Sócios.

\section{Gráfico 5 - Periodicidade das assembléias nos empreendimentos} econômicos solidários da Região Noroeste do RS

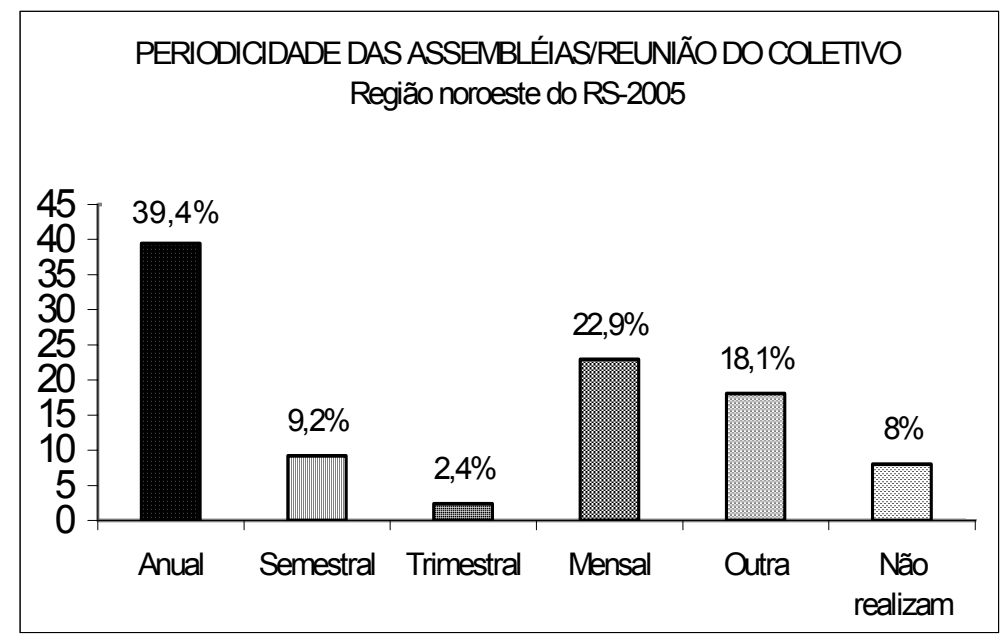

Fonte: Dados Unijuí/mapeamento Sies/Senaes/MTE/2005. 
O segundo dado para avaliar a participação dos associados nos empreendimentos é a periodicidade da realização das assembléias ou reuniões do coletivo de sócios. Foi observado que a maioria realiza essas reuniões mais de uma vez por ano, embora $39,4 \%$ a realizem só anualmente. Há também uma porcentagem significativa $(22,9 \%)$ que as realizam mensalmente, mas esta porcentagem está abaixo da média da região Sul (30\%) e, principalmente, da média nacional, que ficou em 49,2\%. Já na opção outra, que apareceu em $18,1 \%$ dos casos, o grupo realiza a Assembléia quando se faz necessário, ou resolve os problemas que seriam discutidos nessas reuniões durante o diaa-dia no empreendimento. Para finalizar esta questão, podemos dizer que apenas $8 \%$ responderam que não realizam assembléia, ainda que com ressalvas, pois se trata muitas vezes dos grupos informais onde ocorrem as conversas diárias, não excluindo os mesmos do perfil autogestionário.

A grande maioria dos empreendimentos solidários pesquisados (cerca de 80\%) possui uma Diretoria, Conselho Diretor, ou Coordenação. Quando ao Conselho Fiscal, uma obrigação legal para cooperativas e associações, somente $46,9 \%$ declararam possui-lo. No caso de que somente os empreendimentos legalizados tivessem Conselho Fiscal, só um deles não estaria cumprindo com a exigência; mas sabemos, pelo cruzamento dos dados, que alguns empreendimentos informais possuem também essa instância. Isso indica que mais de um empreendimento formal não possui um Conselho Fiscal, desrespeitando assim a legislação. Em somente 17 empreendimentos econômicos solidários encontramos também um Conselho Administrativo, o que mais uma vez reflete, por um lado, o tipo de empreendimento e, por outro, sua semelhança com micro e pequenas empresas. Nenhum empreendimento pesquisado possui um Conselho de Ética.

De qualquer forma, pode-se dizer que $92 \%$ dos grupos mantêm a prática de realização de Assembléia dos sócios. Entretanto, não sabemos ainda qual é a porcentagem de sócios presentes nas assembléias pois, dependendo dos estatutos, a assembléia pode ser realizada em segunda chamada, com qualquer número de participantes. Certos estudos sobre o cooperativismo apontam que "a proporção dos membros que assistem às assembléias são inversamente proporcionais ao número total de membros" (Meister, 1969, p. 30). 


\section{Gráfico 6 - Formas de participação nos empreendimentos econômicos solidários da Região Noroeste do RS}

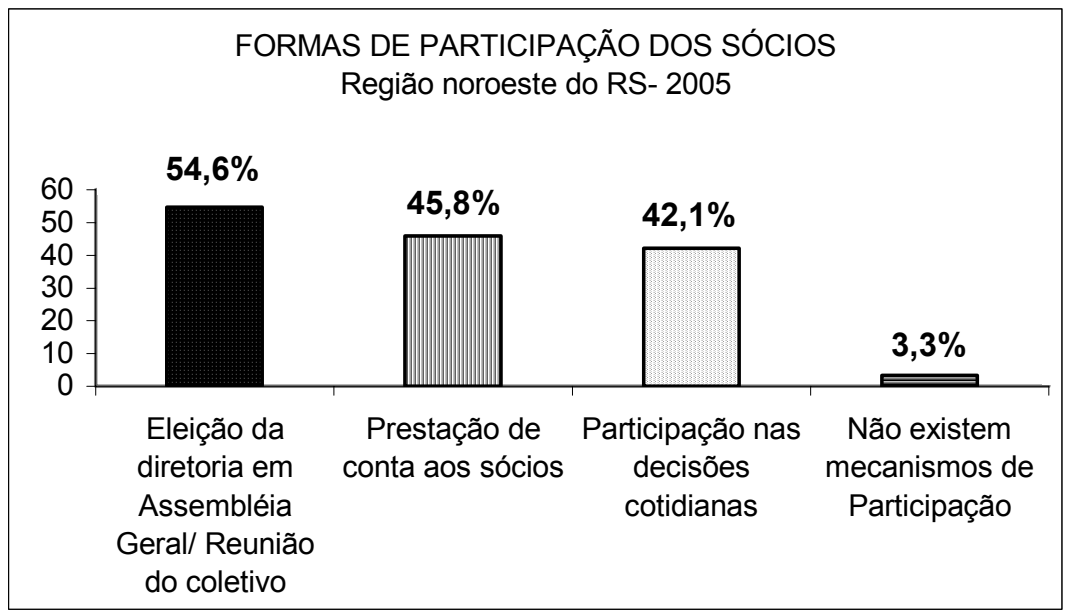

Fonte: Dados Unijuí/mapeamento Sies/Senaes/MTE/2005.

Outra questão referente à gestão dos empreendimentos econômicos solidários é abordada na forma de participação dos sócios nas decisões cotidianas do empreendimento (Tabela 1 e Gráfico 6). Neste caso a alternativa mais citada refere-se à eleição da diretoria em Assembléia Geral/Reunião do Coletivo de Sócios, com 54,6\% (62\% na média nacional). Mas, se considerarmos que somente 216 empreendimentos possuem direção e que 148 realizam a eleição da mesma, podemos afirmar que $65,51 \%$ dos empreendimentos elegem sua diretoria. Em segundo lugar, temos a prestação de contas aos sócios, com $45,8 \%$, muito abaixo da média nacional, que se situa em $62 \%$. Entretanto, o dado que mais chamou a atenção nestas respostas refere-se às participações nas decisões cotidianas do empreendimento, com 42,1\%, pois imaginamos que esta seria uma característica dos grupos informais que representam $52 \%$ do total. Devemos ainda procurar explicação para tal fato, mas desde já podemos levantar a hipótese de que certos grupos têm sua organização baseada nos moldes formais onde existe uma pessoa responsável pela tomada de decisões do grupo. 


\section{Tabela 1 - Forma de participação de sócios(as) nas decisões dos empreendimentos nas Regiões Noroeste Colonial, Fronteira Noroeste, Alto Jacuí e Missões - 2005}

\begin{tabular}{|c|c|c|c|c|}
\hline \multirow{2}{*}{ Forma de participação } & \multicolumn{2}{|c|}{ Citada } & \multicolumn{2}{|c|}{ Não- Citada } \\
\hline & $\mathrm{Fi}$ & $\%$ & $\mathrm{Fi}$ & $\%$ \\
\hline $\begin{array}{l}\text { Acesso aos registros e informações } \\
\text { do empreendimento } \\
\text { Decisão sobre o destino das sobras } \\
\text { e fundos em Assembléia Geral/ } \\
\text { Reunião do Coletivo de Sócios/ as }\end{array}$ & 27 & 10,0 & 244 & 90,0 \\
\hline $\begin{array}{l}\text { Eleição da diretoria em Assembléia } \\
\text { Geral/ Reunião do Coletivo de Sócios/ as }\end{array}$ & 148 & 54,6 & 123 & 45,4 \\
\hline $\begin{array}{l}\text { Prestação de contas aos sócios(as) } \\
\text { em Assembléia Geral/ Reunião } \\
\text { do Coletivo de Sócios/as }\end{array}$ & 124 & 45,8 & 147 & 54,2 \\
\hline $\begin{array}{l}\text { Contratações e remunerações definidas } \\
\text { em Assembléia Geral/ Reunião } \\
\text { do Coletivo de Sócios/as }\end{array}$ & 8 & 3,0 & 263 & 97,0 \\
\hline $\begin{array}{l}\text { Plano de trabalho definido } \\
\text { em Assembléia Geral/ Reunião } \\
\text { do Coletivo de Sócios/as }\end{array}$ & 34 & 12,5 & 237 & 87,5 \\
\hline $\begin{array}{l}\text { Participação nas decisões cotidianas } \\
\text { do empreendimento }\end{array}$ & 114 & 42,1 & 157 & 57,9 \\
\hline $\begin{array}{l}\text { Não existem mecanismos } \\
\text { de participação }\end{array}$ & 9 & 3,3 & 262 & 96,7 \\
\hline
\end{tabular}

Fonte: Dados Unijuí/mapeamento Sies/Senaes/MTE/2005.

Quanto ao acesso dos sócios aos registros e informações do empreendimento, a porcentagem é muito baixa (10\%), enquanto que a média nacional é muito alta $(60 \%)$. O distanciamento é tão grande que merece uma análise cuidadosa, que aqui não temos condição de realizar, mas podemos supor que a grande informalidade na qual vivem $52 \%$ dos empreendimentos deixa vislumbrar uma ausência de registros no seio desses grupos.

Outra análise que o cruzamento dos dados nos permitiu fazer foi que os $3 \%$ de empreendimentos que afirmaram que as contratações e remunerações 
são definidas em assembléia são formais, ou seja, cooperativas e associações. Esta porcentagem é muito baixa perto dos $48 \%$ de grupos formais. Sendo assim, compreende-se que $45 \%$ dos empreendimentos formais não definem em assembléia geral as suas contratações e remunerações. A média nacional de empreendimentos econômicos solidários nos quais acontece a participação dos sócios para definir contratação e remuneração é um pouco mais alta, ao redor de $11 \%$, mas é o assunto a respeito do qual, também nacionalmente, a participação dos sócios continua sendo a menor entre todos. Novas investigações devem indicar em quantos destes empreendimentos existe de fato contratação de trabalhadores, pois não é sempre o caso. Mesmo assim, podemos afirmar que, em geral, as remunerações não são discutidas em reuniões. Trata-se com certeza de uma questão sensível, na qual o mercado e a tradição ditam as regras e cuja decisão é de responsabilidade da direção.

Também vale destacar os 9 empreendimentos onde não existem mecanismos de participação, e que representam 3,3\% do total, sendo estes, em sua quase totalidade, grupos novos, ainda em formação, que entraram em funcionamento a partir do ano de 2004 e não tinham ainda definido de que forma os associados iriam participar.

Assim, pode-se concluir que, em princípio, nos empreendimentos econômicos solidários pesquisados, todos os sócios têm algum tipo de participação em uma ou outra decisão que afeta o empreendimento ou, pelo menos, estão informados sobre as contas do mesmo.

\section{Algumas considerações finais}

Voltando ao nosso objetivo inicial, que era caracterizar até que ponto os empreendimentos econômicos considerados de economia solidária da Região Noroeste do RS exerciam práticas democráticas e autogestionárias, podemos perceber, na análise dos resultados obtidos através da pesquisa, que a questão é bastante complexa.

O primeiro ponto a ser examinado é o da democracia formal, representada pela assembléia dos sócios e eleição dos administradores e outros responsáveis. Essa exigência mínima de práticas democráticas não é cumprida em todos os empreendimentos, pois $8 \%$ dos empreendimentos não realizam sequer assembléia dos sócios. Quanto à eleição da diretoria, 45,4\% dos empre- 
endimentos não a realizam, porém, não podemos esquecer que $20,3 \%$ destes nem possuem diretoria, o que torna impossível a realização da eleição. Estariam estes grupos na pré-história da democracia? A questão merece sérias reflexões. O convívio com alguns destes grupos de produção mostra que existe uma liderança tacitamente aceita, no que poderíamos chamar de democracia por consentimento. Certas lideranças são tradicionais, como nos casos dos clubes de mães; das pastorais, onde a líder é a agente pastoral; da agente de saúde; ou ainda, da responsável que faz a mediação com a instituição de apoio, seja a prefeitura, a igreja, etc. O líder é aceito pelo grupo, pois é considerado o sujeito com mais condições objetivas para levar a bom termo as atividades do empreendimento. Caso os membros não queiram mais a liderança, esta rejeição nem sempre é verbalizada em reunião, mas leva a atitudes como o descumprimento do acordado ou a desistência dos sócios em participar. Isto expressa uma ausência de democracia? Com certeza não se trata de democracia participativa, os trabalhadores não verbalizam o que pensam, mas existe uma aceitação ou reprovação tácita. Assim, por exemplo, percebemos, entre os catadores, uma real vontade de formar uma associação, mas na hora de votar poucos se pronunciam. Não é o que se espera de um grupo solidário, pois a solidariedade nesta economia deveria estabelecer-se entre iguais, para escapar das práticas caritativas e assistencialistas. No entanto, os trabalhadores fazem parte do grupo por vontade própria, por encontrar nele certas satisfações.

Há na origem uma vontade de democracia. Como vimos, muitas decisões são tomadas de maneira cotidiana na rotina do dia a dia. Nesses grupos informais, as atividades produtivas e da vida familiar se entrelaçam. Os associados são parentes, vizinhos, amigos. Os lugares de trabalho são moradias ou sedes de igrejas, bairros, etc., misturando relações de trabalho com relações de afinidades de diversas ordens. Às vezes a imaturidade do grupo leva a que se trate mais de uma reunião de individualidades, onde ninguém se sente responsável pelo todo, mas cobra o sucesso ou o fracasso da empreitada de cada um e, principalmente, do líder e das instituições de apoio: prefeituras, universidades, igrejas, etc. As atividades econômicas deixam muito a desejar e existe uma clara defasagem entre as expectativas do grupo e os resultados efetivos. Isto leva à desistência de vários trabalhadores e entrada de novos.

Mas onde a diretoria está eleita, podemos afirmar que se trata de lideranças democráticas? Formalmente sim, mas de fato qual é a participação, o 
controle exercido pelos sócios? Muitas lideranças assumem todas as responsabilidades e tomam decisões com a ratificação do grupo, mas este, no caso de fracasso, crucifica o líder e o considera como responsável por todos os problemas, sem analisar a parte de responsabilidade que possui no processo.

O tipo ideal de autogestão, como seu nome indica, não se encontra na realidade, mas tão somente no plano das idéias. Segundo o princípio idealizado, cada trabalhador deveria participar, em todo momento, de todas as decisões tomadas no empreendimento do qual é sócio. Na maioria dos casos, porém, isto não acontece, pois muitas decisões são tomadas por representantes eleitos, conselho diretor, conselho administrativo, de gestão, comissões específicas, etc., e cada setor pode gozar de uma certa autonomia. Vários estudos apontam para as dificuldades presentes na formação de uma cultura autogestionária entre os trabalhadores da economia solidária (Vieitez, 2001; Gaiger, 2003; Lima, 2004).

Por outro lado, o mercado e as condições socioeconômicas e culturais nas quais esses trabalhadores se encontram não permitem uma total liberdade de ação; pelo contrário, muitas vezes são as condições externas que ditam as escolhas e não os desejos ou princípios pelos quais se regem, em tese, esses empreendimentos econômicos solidários (Lisboa, 2005).

Nas universidades e empresas capitalistas, o termo autogestão difundiuse com a globalização das técnicas de administração; no entanto, seu significado ainda é bastante impreciso. Algumas vezes se relaciona com os processos produtivos de uma fábrica, outras vezes com a descrição de um fenômeno político de escolha de dirigentes, mas, de maneira geral, a autogestão está mais relacionada a métodos e técnicas administrativas. De acordo com Faria (1987) e Guimarães (1995), é possível traçar uma diferença entre as estratégias do capital (ou gerenciais) e as estratégias dos trabalhadores.

É evidente que apenas a participação nos empreendimentos econômicos solidários não permite uma real emancipação dos trabalhadores, pois, como vimos, não existe liberdade de decisão, há concorrência em todos os níveis e a legislação traz inúmeros entraves como, por exemplo, o número mínimo de 20 associados para formar uma cooperativa, ou seja, o mercado e o Estado impõem determinações de toda ordem. Marx já afirmava que "a condição de participante das decisões na empresa não seria suficiente, cabendo uma indis- 
pensável participação nos mecanismos de controle da sociedade" (Apud Novaes, 2005, p. 124).

A autogestão e as relações democráticas nos empreendimentos econômicos solidários são, no entanto, um exercício democrático que tende a superar a divisão entre tarefas manuais e intelectuais e entre a execução e a concepção, base das desigualdades e da exploração no seio dos processos produtivos e, como tal, devem ser incentivados.

O trabalho associado é uma forma de ter acesso ao exercício da democracia, e como tal uma prática cidadã, que abre possibilidade para garantir outros direitos, ou a luta pela suas conquistas, sem os quais não haverá desenvolvimento humano.

\section{Referências}

ALBUQUERQUE, Paulo Peixoto de. Autogestão. In: CATTANI, Antônio D. (Org.). A outra economia. Porto Alegre: Veraz Editores, 2003. p. 20-26.

ASSOCIAÇÃO NACIONAL DE TRABALHAODORES E EMPRESAS DE AUTOGESTÃO (Anteag). Autogestão, construindo uma nova cultura nas relações de trabalho. 2. ed. São Paulo: Espalhafato Comunicação e Produção, 2000.

FARIA, José Henrique de. Comissões de fábrica: poder e trabalho nas unidades produtivas. Curitiba: Criar Edições, 1987.

GAIGER, L. I. Eficiência sistêmica. In: CATTANI Antônio D. (Org.). A outra economia. Porto Alegre: Veraz Editores, 2003. p. 125-130.

GUIMARÃES, V. N. Novas tecnologias de produção de base microeletrônica e democracia industrial: estudo comparativo de casos na indústria mecânica de Santa Catarina. 1995. Tese (Doutorado). Universidade Federal de Santa Catarina, Florianópolis, 1995.

Lei do Cooperativismo Brasileiro (1971). Informações gratuitas. Disponível em: $<$ Www.cooperativa.com.br/sm_legislacao.asp $>$.

LIMA, Jacob Carlos. O trabalho autogestionário em cooperativas de produção: o paradigma revisitado. Revista Brasileira de Ciências Sociais, v. 19, n. 56, p. 45-62, out. 2004.

LISBOA, Armando de Melo. Economia solidária e autogestão: imprecisões e limites. Revista de Administração de Empresa, Rio de Janeiro, p. 109-115, jul.-set. 2005.

MEISTER, Albert. Los sistemas cooperativos: democracia ou tecnocracia? Barcelona: Editorial Nova Terra, 1969. 
MINISTÉRIO DO TRABALHO, Senaes. Sistema Nacional de Informações em Economia Solidária (Sies): Anexo 1. Termo de Referência. Brasília, 2004.

NASCIMENTO, Cláudio. Autogestão e economia solidária. Outros valores. Cadernos da Cidade do Futuro. Florianópolis, v. 1, n. 2, 2000.

NOVAES, Henrique Tahan. Para além da apropriação dos meios de produção? $\mathrm{O}$ processo de adequação sócio-técnica em fábricas recuperadas. Dissertação (Mestrado em Política Científica e Tecnológica) - Instituto de Geociências, Universidade Estadual de Campinas, Campinas, 2005.

SACHS, Ignacy. Desenvolvimento includente, sustentável, sustentado. Rio de Janeiro: Garamond, 2004.

SARRIA, Ana Mercedes Icaza. Solidariedade, autogestão e cidadania: mapeando a economia solidária no Rio Grande do Sul. In: GAIGER, Luiz Inácio (Org.). Sentidos e experiências da economia solidária no Brasil. Porto Alegre: Editora da Ufrgs, 2004. p. 17-53.

SENAES. Atlas da economia solidária no Brasil. Brasília: MTE/Senaes, 2005.

SINGER, Paul; SOUZA, André Ricardo de (Orgs.). A economia solidária no Brasil: a autogestão como resposta ao desemprego. São Paulo: Contexto, 2000.

VIEITEZ, Cândido Giraldez; DAL RI, Neusa M. Trabalho associado: cooperativas e empresas de autogestão. Rio de Janeiro: DP\&A, 2001.

VIEITEZ, Cândido Giraldez et al. Autogestão e cogestão: instrumental necessário. In: Assoaciação nacional de trabalhadores e empresas de autogestão (Anteag). Empresa social e globalização. Administração autogestionária: uma possibilidade de trabalho permanente. São Paulo: Anteag, 1998. 